\title{
Ethnic disparities in asthma treatment and outcomes in children aged under 15 years in New Zealand: analysis of national databases
}

\author{
Todd D Gillies', Andrew M Tomlin', *Susan M Dovey², Murray W Tilyard ${ }^{1,2}$ \\ Best Practice Advocacy Centre, Dunedin, New Zealand \\ ${ }^{2}$ General Practice and Rural Health, University of Otago, Dunedin School of Medicine, Dunedin, New Zealand
}

Originally received 10th February 2013; resubmitted 21st March 2013; revised 5th May 2013; accepted 13th May 2013; online 12th August 2013

\begin{abstract}
Background: Mãori and Pacific children experience poorer outcomes relating to asthma management than other ethnicities. Aims: To measure recommended treatment and outcomes for asthma in all New Zealand children by age, sex, and ethnic group.

Methods: Children aged $<15$ years dispensed $\geq 2$ asthma medicines $(N=80,514)$ were identified from the national pharmaceutical claims database. We measured the number of children dispensed oral steroids $\geq 2$ times and hospital admissions with a primary diagnosis of asthma and compared asthma treatment steps and hospitalisation by age and ethnicity.

Results: $16.0 \%$ of children were dispensed asthma medicines, $9.2 \%$ were dispensed medicine $\geq 2$ times, $3.6 \%$ of children were hospitalised at least once for asthma and $98.9 \%$ of admissions were acute. Mãori (OR $1.46,95 \% \mathrm{Cl} 1.41$ to 1.51$)$ and Pacific children (OR 2.38, 95\% Cl 2.28 to 2.47) were more likely to remain on the lowest step of treatment. At all steps of treatment, Mãori and Pacific children had higher rates of oral steroid use. In all age groups, more Mãori children (5.1\%, OR 1.88, $95 \% \mathrm{Cl} 1.73$ to 2.04$)$ and Pacific children $(5.6 \%$, OR $2.05,95 \% \mathrm{Cl} 1.84$ to 2.29$)$ were hospitalised for asthma than children of other ethnicities (2.8\%).

Conclusions: Mãori and Pacific children are less likely to have their treatment escalated to a higher step than other children. They are also more likely to use oral steroids to control asthma exacerbations and be admitted to hospital for severe asthma episodes. New Zealand databases can be used to monitor these outcomes.

(C) 2013 Primary Care Respiratory Society UK. All rights reserved.

TD Gillies et al. Prim Care Respir J 2013; 22(3): 312-318

http://dx.doi.org/10.4104/pcrj.2013.00068
\end{abstract}

Keywords asthma, children, ethnic disparities, claims databases, national datasets

\section{See linked editorial by Davidson \& Sheikh on pg 269}

\section{Introduction}

Asthma in children is a chronic condition that is a major cause of hospital admissions and readmissions ${ }^{1,2}$ and is significantly associated with low achievement in school. ${ }^{3}$ In international studies, English speaking countries have been identified as having high rates of selfreported asthma symptoms in children, with New Zealand having the highest rate. ${ }^{4-9}$ National and international guidelines for treatment have changed from being based on asthma severity to gaining control of symptoms through a stepwise escalation of medication, maintaining the lowest level of medication that controls asthma symptoms. ${ }^{10-12}$ Two outcomes indicating poor symptom control and/or inadequate treatment for asthma are hospital admissions for asthma and oral steroid treatment. ${ }^{13}$

The International Study of Asthma and Allergies (ISAAC) study, conducted in 1992/93 and 2001/03, found that 30.2\% of New Zealand children reported having at least one asthma symptom at some time in their life, and that Mãori and Pacific children reported experiencing more severe asthma symptoms than children of other ethnicities. ${ }^{4-6,14,15}$ In the 2006/07 New Zealand Health Survey, $14.8 \%$ of children aged 2-14 years reported having current medicated asthma. ${ }^{16}$ This contrasts with $11.4 \%$ of boys and $7.2 \%$ of girls aged 0-14 reported as having current asthma in the 2011/13 Australian Health Survey. ${ }^{17}$ Previous New Zealand research has found that Mãori and Pacific children, along with younger children and boys, are more likely to be hospitalised for asthma than children of other ethnicities, and that Mãori children were less likely to be prescribed

\footnotetext{
* Corresponding author: Professor Susan M Dovey, Department of General Practice and Rural Health, Dunedin School of Medicine, University of Otago, PO Box 913, Dunedin 9054, New Zealand. Tel: +64 34794135 Fax: +64 34797431 E-mail: susan.dovey@otago.ac.nz
} 
preventive medicines. ${ }^{1,18-20}$ New Zealand population statistics use four main ethnic categories: European/Other, Asian, Mãori, and Pacific Peoples. Asian children comprise only $8.0 \%$ of all New Zealand children aged $<15$ years so, for this analysis, we combined the European/Other and Asian groups (69.2\% of all children) to draw comparisons with Mãori (20.4\%) and Pacific (10.4\%) children.

In 2011 general practice care for children in New Zealand was operating under the policies introduced in 1997 that made general practice care free for children aged $<6$ years. Primary care for older children and for all children after hours is likely to attract a fee. Hospital care is free, however, making it more readily accessible to all children, especially the disproportionately high number of Mãori and Pacific children living in poverty. In the USA, studies have used claims data to identify patients with asthma from medicines dispensed, and hospital admissions indicating a primary diagnosis of asthma to evaluate the effectiveness of treatment guidelines in reducing hospital admissions in patients with asthma. 12,21,22

In this study we aimed to determine whether the poor asthma outcomes that have been previously documented in Mãori and Pacific children compared with children of other ethnicities are also associated with less optimal asthma treatment and lower adherence to guidelines. To achieve this we conducted an analysis of New Zealand's national health databases to establish whether there are ethnic disparities in the way all children in New Zealand are treated for asthma.

\section{Methods}

We used data recorded for the calendar year of 2011 in three national data collections administered by the New Zealand Ministry of Health: the Pharmaceutical Collection which contains records of all subsidised medicines dispensed in community pharmacies in New Zealand; the National Minimum Dataset (Hospital Events) which includes records of hospital admissions in all public and many private hospitals in New Zealand; and the Mortality Collection which registers all deaths occurring in New Zealand.

\section{Asthma treatment and adherence to guidelines}

All records of medicines dispensed to children aged $<15$ years and intended for the treatment of asthma were identified in the Pharmaceutical Collection. Dispensed medicines included salbutamol, terbutaline sulphate, beclomethasone dipropionate, budesonide, fluticasone, budesonide with eformoterol, fluticasone with salmeterol, eformoterol fumarate, salmeterol, prednisolone sodium phosphate, and prednisone. Nasal spray preparations of budesonide and beclomathasone dipropionate and budesonide capsules were excluded because they are not used to treat asthma. Oral leukotriene receptor antagonists are also part of the recommended asthma medication steps, ${ }^{10}$ but they were not funded in New Zealand in 2011 and are not part of our data collection.

In New Zealand, all patients accessing the health system are assigned a unique National Health Index (NHI) code which enables the identification of health records relating to each patient throughout life. For each dispensing episode we ascertained the patient's encrypted NHI code, age at dispensing, sex, and prioritised ethnic group, the medicine's chemical and formulation name, the date of dispensing, and the number of prescription items dispensed. Patients are able to specify up to three ethnic groups. If any of these are Mãori or Pacific Peoples, then the patient is assigned to these groups in the ethnicity fields of national databases. From the total of 583,346 asthma medicines dispensed to children aged $<15$ years we excluded 10,949 records where an $\mathrm{NHI}$ code or prescribing doctor was not recorded $(1.9 \%)$ and 28 records $(<0.1 \%)$ relating to patients with inconsistent recording of sex.

\section{Definition of asthma patients}

We defined a child with asthma as anyone aged $<15$ years who was dispensed any of the medicines in the study (excluding oral steroids) $\geq 2$ times in the 2011 calendar year. The intention was to exclude children using inhalers short-term for reasons other than asthma, such as short-acting $\beta_{2}$-agonist (SABA) treatment for bronchiolitis. Similar methods have been employed previously to define a cohort of asthma patients, as the prescription of multiple asthma items implies a diagnosis of asthma. ${ }^{21}$

We grouped patients into one of four mutually exclusive treatment groups indicating a diagnosis of asthma. The first three groups represent treatment steps adapted from the British Guideline on the Management of Asthma ${ }^{10}$ and are consistent with recommendations for the treatment of childhood asthma in New Zealand (Table 1). ${ }^{11}$ Steps 1-3 indicate increasing asthma severity. We also constructed a fourth group which consisted of children receiving $\geq 2$ dispensings of any combination of asthma medications (excluding oral steroids) not specified in the first three treatment steps.

\section{Asthma health outcomes}

To investigate asthma-related outcomes, the encrypted $\mathrm{NHI}$ code

Table 1. Asthma treatment groups

\begin{tabular}{ll} 
Treatment step & Definition \\
\hline Step 1: Mild intermittent asthma & At least two SABA inhalers dispensed in a 12-month period \\
\hline Step 2: Regular preventer therapy & One or more ICS inhalers in addition to two SABA inhalers in a 12-month period \\
\hline Step 3: Initial add-on therapy & $\begin{array}{l}0-4 \text {-year-olds: Add oral leukotriene receptor antagonist } \\
\text { 5-14-year-olds: One or more LABA inhalers in addition to two SABA inhalers and ICS inhaler/one } \\
\text { or more combination LABA/ICS inhalers in addition to two or more SABA inhalers }\end{array}$ \\
\hline Unspecified: Not a recommended step & $\begin{array}{l}\text { Two or more dispensings of any combination of asthma medications (excluding oral steroids) as } \\
\text { not previously specified. }\end{array}$ \\
\hline
\end{tabular}

ICS=inhaled corticosteroid, LABA=long-acting $\beta_{2}$-agonist, SABA=short-acting $\beta_{2}$-agonist, combination=combined ICS/LABA inhaler

Inhaled leukotriene receptor antagonists were not funded in New Zealand in 2011. 
was used to link patient records in the Pharmaceutical Collection with hospital admission records in the National Minimum Dataset (Hospital Events). The Hospital Events dataset includes admission and discharge dates, admission type, primary and secondary diagnoses, and procedure codes. Data for all inpatient admissions with a primary diagnosis of asthma (ICD-9-CM code 493) in children aged $<15$ years were collated. We excluded admissions coded as transfers between hospital facilities. The NHI codes were also used to identify 28 children using asthma medicines who died from any cause during the study year. As the death diagnosis was not yet available in the mortality data for the 2011 year to determine asthma-related deaths, we excluded these children from subsequent analyses.

\section{Statistical analysis}

We calculated the proportion of all New Zealand children in each treatment group for the three ethnic groups of Mãori, Pacific Peoples, and European/Other and in three 5-year age bands from 0 to 14 years. Population denominators were taken from population estimates made by the New Zealand Statistics Department. To measure health outcomes for children in each demographic group, we determined the proportion of children dispensed oral steroids $\geq 2$ times and the proportion admitted to hospital with a primary diagnosis of asthma. Children of European/Other ethnicities were the reference group in all calculations of odds ratios (ORs), and ORs were calculated with regard to the total estimated population in each age and ethnicity group.

\section{Results}

Of the total population of 872,591 children aged $<15$ years in New Zealand in 2011, 139,856 (16.0\%) were dispensed any of the medicines in this study (excluding oral steroids) at least once in 2011 with 80,514 (9.2\%) receiving treatment for asthma as defined by the four asthma treatment groups (Figure 1).The asthma study group therefore includes $8.7 \%$ of the total New Zealand Mãori population aged $<15$ years, $9.9 \%$ of Pacific children, and $9.4 \%$ of children of
European or other ethnicities. These children represented $10.5 \%$ of all New Zealand boys and $7.8 \%$ of girls. Children receiving more than one asthma medication (the study group) were different from children receiving only one asthma medication in that they were more likely to be male (58.4\% of the study group and $55.8 \%$ of children receiving only one asthma medicine were male, $p<0.001$ ), older (mean age 6.78 years vs. 5.59 years, $p<0.001$ ) more likely to be European $(66.5 \%$ vs. $65.8 \%, p=0.010)$ and Mãori $(23.6 \%$ vs. $22.3 \%, p<0.001)$, and less likely to be of Pacific Island ethnicity (9.9\% vs. $11.9 \%, p<0.001)$.

Table 2 shows asthma treatment levels for Mãori and Pacific children with reference to children of other ethnicities. Both Mãori and Pacific children aged $<5$ years were more likely to be treated for asthma than other ethnic groups, but less likely in the 5-9 year and 10-14 year age groups. The proportion of Mãori boys and girls treated for asthma were both lower than for boys and girls of European/Other ethnicity. Mãori (OR 1.56, 95\% Cl 1.51 to 1.62) and Pacific children (OR 2.70, 95\% Cl 2.59 to 2.82) aged $<10$ years were more likely to be treated with SABA alone (step 1) than children of other ethnicities. Relatively more Mãori and Pacific children aged $<5$ years were treated with SABA and inhaled corticosteroids (step 2) than other ethnic groups but a smaller proportion in the older age groups. More children of European/Other ethnicity received add-on therapy involving a longacting $\beta_{2}$-agonist (step 3 ) than Mãori or Pacific children (Figure 2). In the older age groups there was evidence that proportionally fewer Mãori and Pacific children had their treatment escalated to a higher step than European/Other children.

Table 3 shows differences between ethnic groups in the number of patients experiencing exacerbations of asthma as measured by multiple dispensings of oral steroids. Children aged $<5$ years were more than twice as likely to use oral steroids as children aged 5-9 years (OR 2.59, $95 \% \mathrm{Cl} 2.49$ to 2.70 ) and more than five times as likely as children aged $10-14$ years (OR $5.50,95 \% \mathrm{Cl} 5.20$ to 5.82 ).

Figure 1. New Zealand children by asthma treatment group and medicine dispensed. ICS=inhaled corticosteroid, LABA=long-acting $\beta_{2}$-agonist, SABA=short-acting $\beta_{2}$-agonist

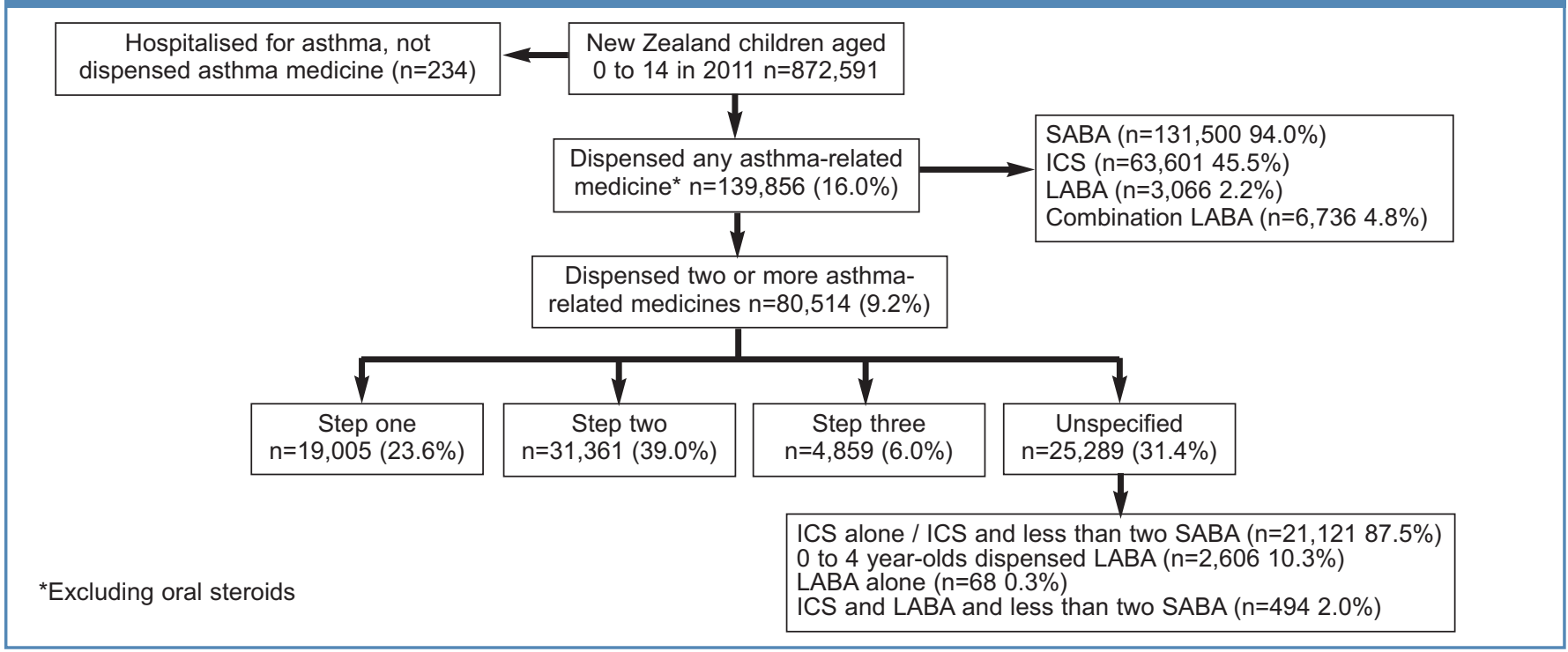


Table 2. Odds ratios for asthma treatment step by ethnic group and age

\begin{tabular}{|c|c|c|c|c|c|}
\hline & \multicolumn{2}{|l|}{ Mãori } & \multicolumn{2}{|c|}{ Pacific Peoples } & \multirow{2}{*}{$\begin{array}{l}\text { European/Other* } \\
\mathrm{N}(\%)\end{array}$} \\
\hline & $\mathrm{N}(\%)$ & OR $(95 \% \mathrm{Cl})$ & $\mathrm{N}(\%)$ & OR $(95 \% \mathrm{Cl})$ & \\
\hline \multicolumn{6}{|l|}{ 0-4-year-olds } \\
\hline Step 1 & $3,865(5.2)$ & $1.83(1.75$ to 1.91$)$ & $2,345(9.4)$ & $3.43(3.26$ to 3.61$)$ & $5,323(2.9)$ \\
\hline Step 2 & $3,305(4.5)$ & $1.14(1.09$ to 1.19$)$ & $1,205(4.8)$ & $1.23(1.16$ to 1.31$)$ & 7,161 (3.9) \\
\hline Step 3 & $0(0.0)$ & - & $0(0.0)$ & - & $0(0.0)$ \\
\hline Unspecified & $1,594(2.2)$ & $0.70(0.66$ to 0.74$)$ & $408(1.6)$ & $0.52(0.47$ to 0.58$)$ & $5,582(3.1)$ \\
\hline Total & $8,764(11.8)$ & 1.22 (1.19 to 1.25$)$ & $3,958(15.8)$ & 1.70 (1.64 to 1.77$)$ & $18,066(9.9)$ \\
\hline Estimated population & 74,020 & & 25,024 & & 18,1951 \\
\hline \multicolumn{6}{|l|}{ 5-9-year-olds } \\
\hline Step 1 & $1,083(1.5)$ & $1.03(0.96$ to 1.11$)$ & $699(2.4)$ & $1.72(1.58$ to 1.87$)$ & $2,643(1.4)$ \\
\hline Step 2 & $2,652(3.6)$ & $0.84(0.80$ to 0.88$)$ & $1,055(3.6)$ & $0.86(0.80$ to 0.92$)$ & $7,861(4.2)$ \\
\hline Step 3 & $514(0.7)$ & $0.81(0.73$ to 0.89$)$ & $138(0.5)$ & 0.55 (0.47 to 0.66$)$ & $1,595(0.9)$ \\
\hline Unspecified & $1,909(2.6)$ & $0.62(0.59$ to 0.65$)$ & $638(2.2)$ & $0.53(0.49$ to 0.57$)$ & $7,635(4.1)$ \\
\hline Total & $6,158(8.3)$ & $0.76(0.74$ to 0.79$)$ & $2,530(8.7)$ & $0.81(0.77$ to 0.84$)$ & $19,734(10.6)$ \\
\hline Estimated population & 74,418 & & 29,069 & & 18,6876 \\
\hline \multicolumn{6}{|l|}{ 10-14-year-olds } \\
\hline Step 1 & $652(0.9)$ & $0.88(0.80$ to 0.96$)$ & $272(1.0)$ & $0.96(0.85$ to 1.10$)$ & $2,123(1.0)$ \\
\hline Step 2 & $1,630(2.3)$ & $0.80(0.75$ to 0.84$)$ & $673(2.5)$ & $0.87(0.80$ to 0.94$)$ & $5,819(2.9)$ \\
\hline Step 3 & $476(0.7)$ & $0.68(0.61$ to 0.75$)$ & $130(0.5)$ & $0.49(0.41$ to 0.58$)$ & $2,006(1.0)$ \\
\hline Unspecified & $1,325(1.9)$ & 0.65 (0.61 to 0.69$)$ & $430(1.6)$ & $0.55(0.50$ to 0.61$)$ & $5,768(2.8)$ \\
\hline Total & $4,083(5.8)$ & $0.73(0.70$ to 0.75$)$ & $1,505(5.6)$ & $0.71(0.67$ to 0.74$)$ & $15,716(7.7)$ \\
\hline Estimated population & 71,004 & & 26,977 & & 20,3252 \\
\hline \multicolumn{6}{|l|}{ Sex (all ages) } \\
\hline Boys & $10,912(9.7)$ & 0.89 (0.87 to 0.91$)$ & $4,531(10.9)$ & $1.01(0.98$ to 1.05$)$ & $31,564(10.8)$ \\
\hline Girls & $8,093(7.6)$ & $0.69(0.68$ to 0.71$)$ & $3,462(8.7)$ & $0.81(0.78$ to 0.84$)$ & $21,952(10.5)$ \\
\hline
\end{tabular}

$N(\%)=$ number of children (percentage of estimated population). *Reference group for comparisons with Mãori and Pacific Peoples

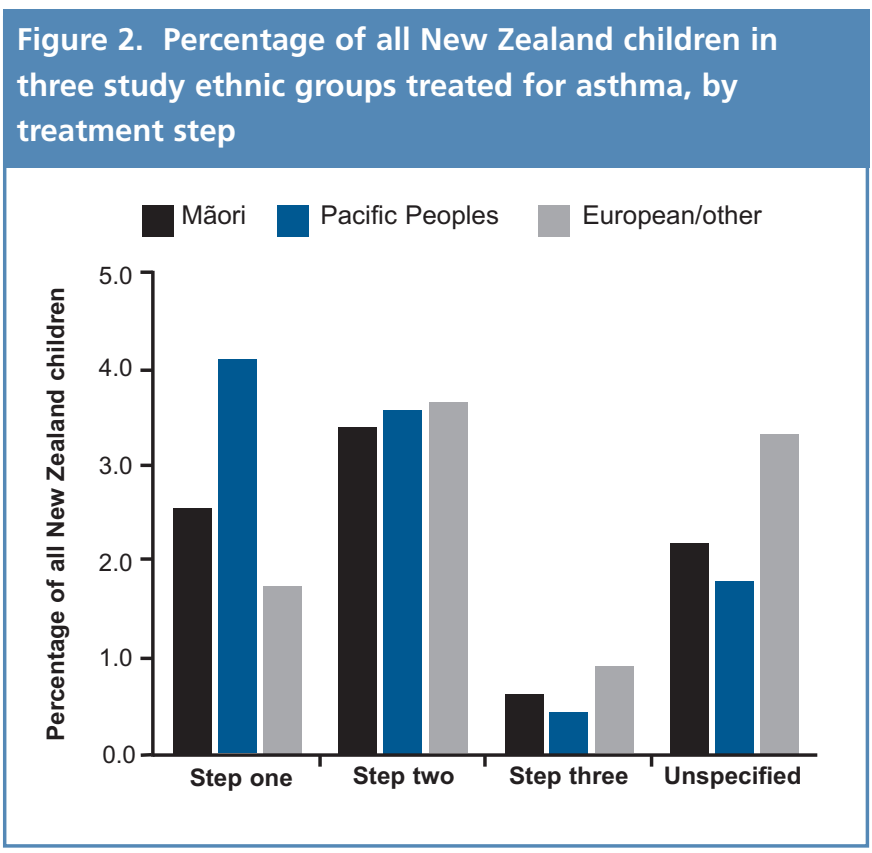

Compared with both children of European/Other ethnicity and Mãori children, Pacific children were more likely to use oral steroids than children of other ethnicities across all age groups and treatment steps. Overall, more children treated on step 3 used oral steroids $\geq 2$ times $(27.1 \%)$ than children on step $2(25.2 \%$, OR $1.10,95 \% \mathrm{Cl}$
1.03 to 1.18). Similarly, more children on step 2 had multiple prescriptions for oral steroids than children on step 1 (20.5\%, OR $1.30,95 \% \mathrm{Cl} 1.25$ to 1.36$)$, indicating increasing occurrence of severe asthma exacerbations with increasing severity of asthma.

Across all ethnic groups, $5.8 \%$ of $0-4$-year-olds, 3.1\% of 5-9year-olds and $1.2 \%$ of $10-14$-year-olds were hospitalised with a primary diagnosis of asthma (Table 4). In all age groups, Mãori and Pacific children were significantly more likely to be admitted to hospital with asthma than children in the European/Other ethnic group. Mãori and Pacific children were also more likely to be admitted to hospital than children of other ethnicities at all treatment steps. In total there were 3,874 asthma admissions for children in one of the four groups, with $98.9 \%$ of these being acute admissions via accident and emergency departments. Figure 3 shows the disparities in oral steroid use and hospital admissions between Mãori and Pacific children and children of other ethnic groups. At all steps of treatment, Mãori and Pacific children had higher rates of oral steroid use and a significantly greater proportion of Mãori children (5.1\%, OR 1.88, 95\% Cl 1.73 to 2.04 ) and Pacific children (5.6\%, OR 2.05, 95\% Cl 1.84 to 2.29 ) overall were hospitalised for asthma than European/Other children (2.8\%).

We also identified a further 603 unplanned hospital admissions for asthma by 570 children aged $<15$ years who were not in any of our asthma treatment groups. Of these children, 210 (36.8\%) were Mãori and 129 (22.6\%) were Pacific Peoples. In total, 53.7\% of all 
Table 3. Odds ratios for $\geq 2$ oral steroid dispensings by ethnic group and age

\begin{tabular}{|c|c|c|c|c|c|}
\hline & \multicolumn{2}{|l|}{ Mãori } & \multicolumn{2}{|c|}{ Pacific Peoples } & \multirow{2}{*}{$\begin{array}{l}\text { European/Other* } \\
\mathrm{N}(\%)\end{array}$} \\
\hline & $\mathrm{N}(\%)$ & OR $(95 \% \mathrm{Cl})$ & $\mathrm{N}(\%)$ & OR $(95 \% \mathrm{Cl})$ & \\
\hline \multicolumn{6}{|c|}{ 0-4-year-olds } \\
\hline Step 1 & $1,036(26.8)$ & $0.96(0.88$ to 1.06$)$ & $789(33.6)$ & $1.38(1.24$ to 1.53$)$ & $1,431(26.9)$ \\
\hline Step 3 & $0(0.0)$ & - & $0(0.0)$ & - & $0(0.0)$ \\
\hline Unspecified & $296(18.6)$ & $0.90(0.78$ to 1.03$)$ & $101(24.8)$ & $1.29(1.02$ to 1.64$)$ & $1,131(20.3)$ \\
\hline Total & $2,738(31.2)$ & $1.05(1.00$ to 1.11$)$ & $1,503(38.0)$ & $1.42(1.32$ to 1.53$)$ & $5,440(30.1)$ \\
\hline Step 1 & $121(11.2)$ & 0.98 (0.79 to 1.23$)$ & $81(11.6)$ & $1.02(0.79$ to 1.33$)$ & $300(11.4)$ \\
\hline Step 2 & $510(19.2)$ & 1.06 (0.95 to 1.19$)$ & $299(28.3)$ & 1.77 (1.53 to 2.04$)$ & $1,439(18.3)$ \\
\hline Step 3 & $208(40.5)$ & 1.27 (1.04 to 1.56$)$ & 55 (39.9) & $1.24(0.87$ to 1.77$)$ & $555(34.8)$ \\
\hline Unspecified & $118(6.2)$ & $0.85(0.70$ to 1.05$)$ & $44(6.9)$ & $0.96(0.70$ to 1.32$)$ & $547(7.2)$ \\
\hline Total & $957(15.5)$ & 1.09 (1.01 to 1.18$)$ & 479 (18.9) & 1.39 (1.25 to 1.55$)$ & $2,841(14.4)$ \\
\hline \multicolumn{6}{|c|}{ 10-14-year-olds } \\
\hline Total & $333(8.2)$ & $1.12(0.99$ to 1.28$)$ & $157(10.4)$ & 1.48 (1.24 to 1.76$)$ & $1,150(7.3)$ \\
\hline
\end{tabular}

Table 4. Odds ratios for hospital admission by ethnic group and age

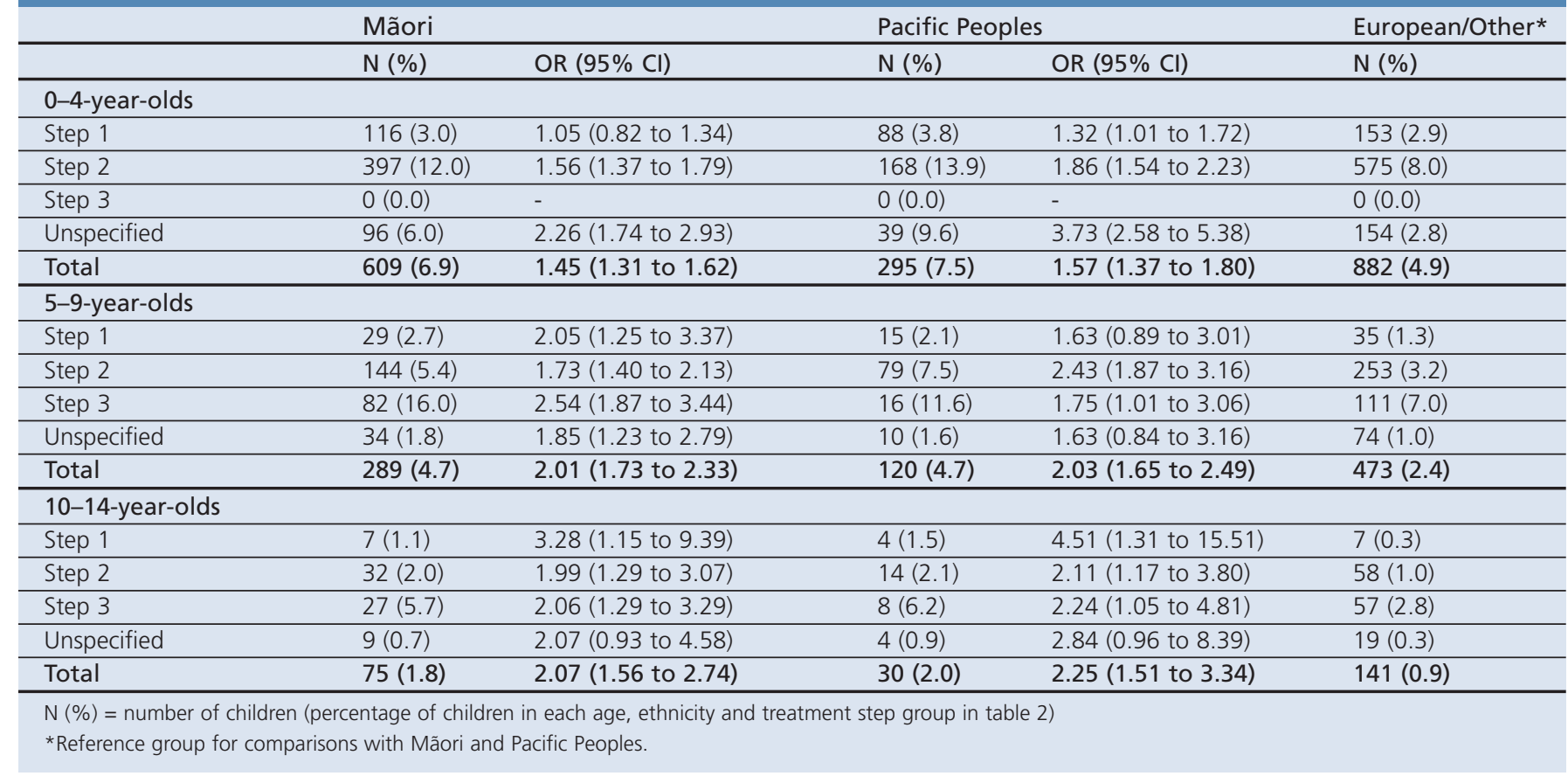

acute asthma admissions in New Zealand were for patients aged $<15$ years, although this age group was only $19.9 \%$ of the total New Zealand population in 2011.

\section{Discussion}

\section{Main findings}

Our findings show that Mãori and Pacific children aged $<5$ years are more likely to be treated for asthma than children of European/other ethnicities. However, in older age groups they are less likely to have their asthma treatment escalated to include inhaled corticosteroids or long-acting $\beta_{2}$-agonists, despite having higher rates of hospital admission for asthma and requiring a larger number of dispensings of oral steroids to control asthma exacerbations. Although similar effects have been shown previously in studies of limited scope, they have never before been demonstrated at the level of the entire country. 
Figure 3. Asthma outcomes for children by ethnicity and treatment step

A. Oral steroids dispensed two or more times

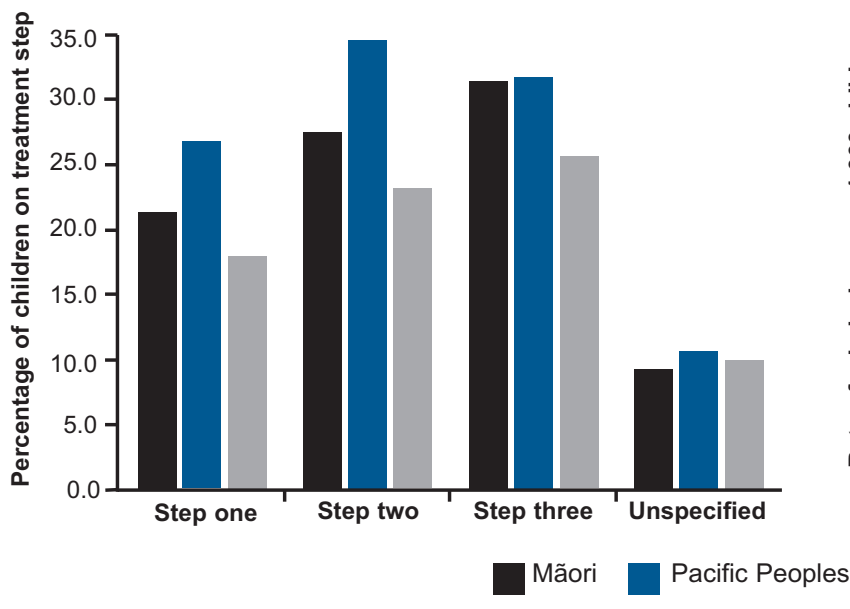

B. Hospital admission rate for asthma

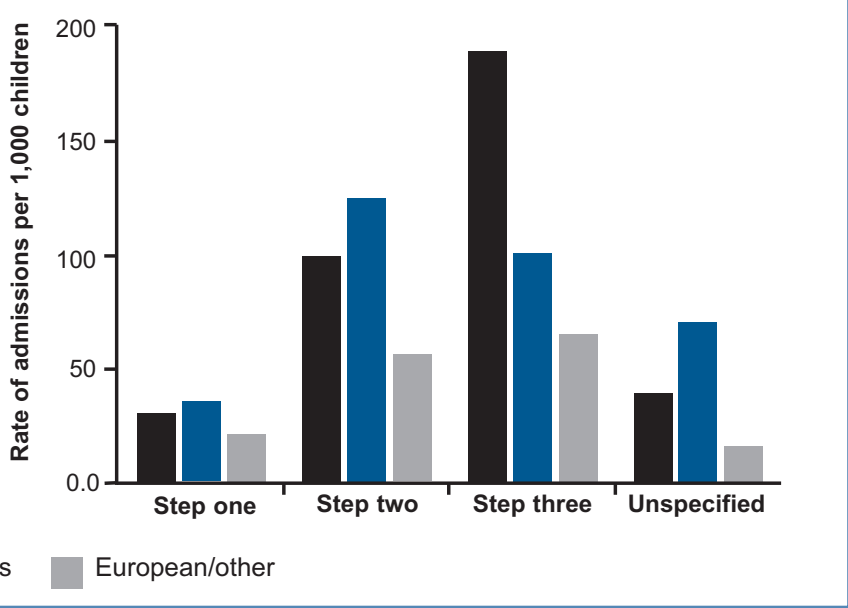

\section{Interpretation of findings in relation to previously published work}

Previous studies have found that Mãori and Pacific children are more likely to experience severe asthma, ${ }^{4,14}$ implying that more Mãori and Pacific children should be on a higher treatment step to control their symptoms. Our results, based on the use of pharmaceutical treatment, showed that this expectation was not realised for Mãori and Pacific children aged $\geq 5$ years where there were more children on step 1 treatment and fewer on step 3 than children of other ethnicities. This may reflect the limitations of using pharmaceutical claims data to describe patient illness, as claims records do not provide clinical information on why a patient was prescribed a medicine or how severe their symptoms may have been. It is also possible that patients who experience symptoms may not seek treatment. ${ }^{23,24}$

Prior research has shown that Mãori and Pacific Peoples in New Zealand have greater difficulty accessing medical care ${ }^{4}$ and, while there are likely to be cultural reasons for this, it is possible that Mãori and Pacific children are more often treated at lower recommended levels of treatment due to poorer access to general practice, especially for children aged $\geq 6$ years whose general practice care is likely to incur a charge. The higher rate of hospitalisation and oral steroid use among Mãori and Pacific children found in this study may indicate less frequent use of general practice services by these children until symptoms become severe. A lack of understanding of medicines, ineffective communication with health providers, and other cultural issues ${ }^{25}$ can lead to a lack of adherence to prescribed treatment among Mãori and Pacific Peoples, which may in turn lead to failure to pick up prescribed medicines or have the correct number of repeat dispensings. In this study, children were classified into groups based on medicines dispensed to patients; in non-compliant patients this may not reflect the intentions of the prescribing doctor. Implications for future research, policy and practice Of the 80,514 children with asthma, 2,914 (3.6\%) were hospitalised at least once with a primary diagnosis of asthma during the study year and almost all admissions were acute. This indicates the importance of controlling asthma symptoms in children with asthma, both to minimise the occurrence of severe asthma episodes and to reduce the burden of demand on acute hospital services.

We also found evidence of proportionately more Mãori and Pacific children being hospitalised with asthma without having been prescribed any medicine in primary care before their admission. This again suggests that innovative policy solutions are needed to address systematic ethnicity-based discrimination in the way New Zealand's health services are planned, managed, and delivered. Although New Zealand, like other countries, strives to meet the World Health Organization's goal for primary health care that is accessible and - ideally - free, the country's regulatory, financing, and organisation has so far failed to deliver on this goal, ${ }^{26}$ making it highly likely that some children's opportunity for optimal health is currently limited. It is possible that overuse of medicines may be as much of a problem as underuse; this needs more investigation.

\section{Strengths and limitations of this study}

We could not provide a robust estimate of the overall prevalence of asthma in children in New Zealand because we studied only asthma that was treated by medications or hospital care. As a consequence of using pharmaceutical claims data to identify children with asthma, our first objective was to positively identify patients with asthma as indicated by use of two asthma medicines. We therefore excluded children who may have been dispensed an asthma medicine for short-term use to treat other conditions such as bronchiolitis. It is possible that we excluded a large number of children with less severe asthma from our study cohort.

However, we identified $16.0 \%$ of all New Zealand children under 15 years of age who were dispensed at least one asthmarelated medicine in 2011 , and $9.2 \%$ of all New Zealand children as having diagnosed asthma through multiple dispensings of asthma medicines. This suggests our study is a reasonably comprehensive representation of asthma care for children because the 2006/07 New Zealand Health Survey ${ }^{16}$ estimated asthma prevalence to be $14.8 \%$ among children aged $2-14$ years and $11.7 \%$ of Australian boys and $7.2 \%$ of girls aged $0-14$ were identified as having asthma 
in the 2011/13 Australian National Health Survey. ${ }^{17}$

In addition, many children with asthma may have been prescribed asthma medicines but did not have these dispensed, and they may not have received the correct number of repeat dispensings. We were also not able to determine the extent to which differences in access to primary care explained the levels of treatment provided to children from different ethnic groups or ages. Most primary care for children aged $<6$ years is free in New Zealand, but charges generally apply for older children and may limit access to general practice for other age groups.

We used odds ratios to measure differences in risks of children of different ethnic groups having different asthma diagnoses and treatment. Because asthma is a relatively common condition in New Zealand, this may have contributed to some overestimation of risk in some cases.

\section{Conclusions}

Our research provides for the first time a description of asthma treatment focusing on all children in New Zealand. We were able to link national datasets recording medicines used in the treatment of asthma and hospital admissions to investigate admission rates for asthma based on recommended guideline levels of treatment. Our findings highlight the disparities in asthma treatment rates and adverse health outcomes experienced by children of Mãori and Pacific descent compared with children of European or other ethnicity. They also indicate that Mãori and Pacific children aged $<5$ years have especially high rates of asthma and adverse health outcomes related to asthma, and these children should receive special attention in policy-making and health service planning.

\section{Handling editor Arnulf Langhammer Statistical review Gopal Netuveli}

Acknowledgements We thank PHARMAC for their permission to use the national Pharmaceutical Collection in this analysis.

Conflicts of interest The authors declare that they have no conflicts of interest in relation to the article.

Contributorship All authors made substantial contributions to conception and design of the study, drafting the article or revising it critically for important intellectual content; and gave final approval of the version to be published. In addition, TDG analysed the data guided by AMT and SMD and produced the first draft of the paper and MWT was responsible for data acquisition.

Funding This research was conducted as a component of the usual employment of the authors by bpac $\mathrm{c}^{12}$ and the University of Otago. $\mathrm{bpac}^{12}$ is a registered charity operating under contracts with PHARMAC and District Health Boards Shared Services (DHBSS) and is co-owned by the University of Otago, ProCare Health Limited, South Link Health, General Practice New Zealand and Pegasus Health.

\section{References}

1. Mitchell EA, Bland JM, Thompson JM. Risk factors for readmission to hospital for asthma in childhood. Thorax 1994;49:33-6. http://dx.doi.org/10.1136/thx.49.1.33

2. Dharmalingam A, Pool I, Baxendine S, Sceats J. Trends and patterns of avoidable hospitalisations in New Zealand: 1980-1997. NZ Med J 2004;117(1198):U976.

3. Liberty KA, Pattemore P, Reid J, Tarren-Sweeney M. Beginning school with asthma independently predicts low achievement in a prospective cohort of children. Chest 2010;138(6):1349-55. http://dx.doi.org/10.1378/chest.10-0543

4. Pattemore PK, Ellison-Loschmann L, Asher Ml, et al. Asthma prevalence in European, Maori, and Pacific children in New Zealand: ISAAC study. Paediatr Pulmonol 2004;37:433-42. http://dx.doi.org/10.1002/ppul.10449

5. Asher MI, Barry D, Clayton T, et al. The burden of symptoms of asthma, allergic rhinoconjunctivitis and atopic eczema in children and adolescents in six New Zealand centres: ISAAC phase one. NZ Med J 2011;114:114-20.

6. Stewart AW, Mitchell EA, Pearce N, Strachan DP, Weiland SK, ISAAC Steering Committee. The relationship of per capita gross national product to the prevalence of symptoms of asthma and other atopic diseases in children (ISAAC). Int $J$ Epidemiol 2001;30:173-9. http://dx.doi.org/10.1093/ije/30.1.173

7. Lai CK, Beasley R, Crane J, et al. Global variation in the prevalence and severity of asthma symptoms: phase three of the International Study of Asthma and Allergies in Children (ISAAC). Thorax 2009;64(6):476-83. http://dx.doi.org/10.1136/thx.2008.106609

8. Wickens K, Crane J, Kemp T, et al. A case-control study of risk factors for asthma in New Zealand children. Aust NZ J Public Health 2001;25(1):44-9. http://dx.doi.org/10.1111/j.1467-842X.2001.tb00549.x

9. OECD. Disease-based indicators: prevalence of diabetes and asthma among children. OECD, 2009. http://www.oecd.org/els/familiesandchildren/43137064.pdf (cited 13 December 2012)

10. Scottish Intercollegiate Guidelines Network (SIGN). British guideline on the management of asthma: a national clinical guide. 2012. http://www.sign.ac.uk/pdf/sign101.pdf (cited 13 December 2012).

11. bpacnz. Diagnosing and managing asthma in children. 2012. http://www.bpac.org.nz/magazine/2012/february/asthma.asp (cited 13 December 2012).

12. Schatz M, Zeiger RS, Vollmer WM, Mosen D, Cook EF. Determinants of future longterm asthma control. J Allergy Clin Immunol 2006;118:1048-53. http://dx.doi.org/10.1016/j.jaci.2006.07.057

13. Chan J, Hui RL, Spence MM. Effects on resource utilisation of adding salmeterol in combination with separately to inhaled corticosteroids. I Manag Care Pharm 2007;13(1):21-7

14. Ellison-Loschmann L, Pattemore PK, Asher Ml, et al. Ethnic differences in asthma prevalence in New Zealand: ISAAC phases I and III. Int J Tuberc Lung Dis 2009;13(6):775-82

15. Asher Ml, Stewart AW, Clayton T, et al. Has the prevalence and severity of symptoms of asthma changed among children in New Zealand? ISAAC phase three. NZ Med J 2008;212(1284):52-63.

16. Ministry of Health. A portrait of health. Key results from the $2006 / 07$ New Zealand health survey. Wellington: Ministry of Health, 2008.

17. Australian Bureau of Statistics. Australian Health Survey: first results, 2011-12. Canberra: Australian Bureau of Statistics. 2012.

18. Mitchell EA. Racial inequalities in childhood asthma. Soc Sci Med 1991;32(7):8316. http://dx.doi.org/10.1016/0277-9536(91)90309-Z

19. Salmond C, Crampton $P$, Hales $S$, Lewis S, Pearce N. Asthma prevalence and deprivation: a small area analysis. J Epidemiol Community Health 1999;53(8):47680. http://dx.doi.org/10.1136/jech.53.8.476

20. Mitchell EA, Asher MI. Prevalence, severity and medical management of asthma in European school children in 1985 and 1991. J Paediatr Child Health 1994;30:398402. http://dx.doi.org/10.1111/j.1440-1754.1994.tb00687.x

21. Schatz M, Cook EF, Nakahiro R, Petitti D. Inhaled corticosteroids and allergy specialty care reduce emergency hospital use for asthma. I Allergy Clin Immunol 2003;111:503-08. http://dx.doi.org/10.1067/mai.2003.178

22. Broder MS, Chang EY, Sapra S. Care of asthma patients in relation to guidelines. Allergy Asthma Proc 2010;31(6):452-60.

http://dx.doi.org/10.2500/aap.2010.31.3369

23. Piecoro LT, Potoski M, Talbert JC, Doherty DE. Asthma prevalence, cost and adherence with expert guidelines on the utilization of health care services and costs in a state Medicaid population. Health Serv Res 2001;36(2):357-71.

24. Smith AK, Ayanian JZ, Covinsky KE, et al. Conducting high-value secondary dataset analysis: an introductory guide and resources. J Gen Intern Med 2011;26(8):920-9. http://dx.doi.org/10.1007/s11606-010-1621-5

25. Garrett J, Fenwick JM, Taylor G, Mitchell E, Stewart J, Rea H. Prospective controlled evaluation of the effect of a community based asthma education centre in a multiracial working class neighbourhood. Thorax 1994;49:976-83. http://dx.doi.org/10.1136/thx.49.10.976

26. Gauld R. The WHO and primary healthcare reform: mind the implementation gap. Int J Clin Pract 2011;65(4):386-90. http://dx.doi.org/10.1111/j.1742-1241.2011.02645.x

\section{Available online at http://www.thepcrj.org}

